\title{
Clinical genetics issues encountered by family physicians
}

\author{
Louise S. Acheson, MD, $M S^{1}$, Kurt C. Stange, $M D, P h D^{2}$, and Stephen Zyzanski, $P h D^{3}$
}

\begin{abstract}
Purpose: To describe the genetics-related clinical issues encountered by family physicians, and the medical problems they referred to genetics consultants. Methods: Questionnaires were mailed to a nationwide, random sample of 498 practicing family physicians, asking how many times in the past year they discussed genetic information about 19 familial or genetic conditions with patients and what proportion of the families with each genetic condition were referred for genetics consultation. Factor analysis was used to group the conditions. Results: The response rate was $38 \%(n=190)$. Respondents were similar to nonrespondents except that more were women. Most family physicians reported discussing the genetics of common cancers, cardiovascular disease, and Alzheimer's disease with two or more patients in the past year. Thirteen percent had referred families for genetics assessment of breast-ovarian cancer but only two made genetics referrals for cardiovascular disease or dementia. $25 \%$ to $50 \%$ of family physicians had addressed genetic issues in at least one family with hemoglobinopathy, a blood clotting disorder, hemochromatosis, mental illness, vision loss or deafness, chromosome abnormality, infertility or pregnancy loss, congenital anomalies, mental retardation, and neurofibromatosis. Most cases were not referred to geneticists. Of respondents, $23 \%$ said that genetics consultation is very difficult to obtain or unavailable and $18 \%$ listed ethical and social dilemmas related to pursuing genetic diagnosis. Conclusion: Nationwide, family physicians address a variety of genetics issues with patients, most frequently consulting geneticists for perinatal conditions and familial cancers. Access to genetics consultation is more difficult in rural areas. These data may be used in organizing genetics services and in planning professional education programs for primary care clinicians. Genet Med 2005:7(7):501-508.
\end{abstract}

Key Words: clinical genetics and primary care, family medicine, genetics services, consultation, referral to Geneticists, ethical, legal, and social issues

Primary care clinicians will be the first contact and source of referral for most patients with genetic concems. ${ }^{1-4}$ Family physicians care for multiple members of the same family, and may therefore be particularly likely to address heritable disorders. ${ }^{5}$ Burgeoning media publicity may lead patients to ask their physicians for information about genetic testing, ${ }^{6-8}$ even though specific knowledge of the genetic bases for many common diseases has yet to develop to the point where genetic testing is clinically applicable. Indeed, emerging interest in the genetics of multifactorial conditions seen frequently in primary care provided impetus for this study. There are few recent published data from non-

\footnotetext{
From the Family Medicine Research Division and Comprehensive Cancer Center, Case Western Reserve University and University Hospitals of Cleveland: ${ }^{1}$ Professor of Family Medicine, Associate Professor of Oncology and Reproductive Biology; ${ }^{2}$ Professor of Family Medicine, Oncology, Sociology, Epidemiology and Biostatistics; Associate Director for Cancer Prevention, Control, and Population Research, Case Comprehensive Cancer Center; ${ }^{3}$ Professor of Family Medicine, Oncology, Epidemiology and Biostatistics; Director, Behavioral Measurement Shared Resource, Case Comprehensive Cancer Center.

Louise S. Acheson, MD, MS, Department of Family Medicine, LC 5036, Case Western Reserve University, 11100 Euclid Avenue, Cleveland, $\mathrm{OH}$ 44106-5036.

Received: May 12, 2005.

Accepted: May 23, 2005.
}

DOI: 10.1097/01.gim.0000177418.24176.9b referral settings that describe the types of genetic information and consultation needed by primary care physicians in everyday practice. ${ }^{1,9-11}$ However, such data are essential for planning services, educational programs, and information resources related to clinical genetics that will be relevant, accessible, and useful for primary care practitioners and their patients.

This study had the following aims: (1) to identify how often a representative sample of US family physicians report addressing the genetic aspects of various heritable conditions during a year of practice; and (2) to identify which medical problems were likely to be referred by family physicians to genetics consultants. We hypothesized that family physicians would encounter a wide variety of medical conditions that they or their patients believe to have a genetic component, but that some conditions would be unlikely to lead to genetics consultation. Barriers to access, low probability of a Mendelian disorder, and lack of evidence about the usefulness of genetic tests for care of some common conditions would limit the likelihood of referral to a geneticist. ${ }^{7,12}$

\section{METHODS}

A brief, anonymous survey questionnaire was mailed in the winter of 2000-2001 to a nationally representative sample of 
practicing family physicians. This survey asked the frequency with which these physicians had addressed genetics issues in patient care during the past year, and what proportion of families with each condition they referred for genetics consultation. This research protocol was approved by the University Hospitals of Cleveland Institutional Review Board.

\section{Survey instrument:}

The questionnaire was designed for brevity in order to maximize response rate. It was titled, "What genetic issues have you encountered recently in your clinical practice?"

The genetics-related questions were as follows:

(1) Aside from routine screening of prenatal patients, how many times in the past year have you identified a need to address a medical condition from a genetic perspective or has a patient asked you about the genetic basis or genetic testing for any of the following medical conditions?

This was followed by a checklist of 19 categories of conditions, with response options of $0,1,2$, and more than 2 times in the past year.

(2) What proportion of the families with each condition did you refer to a geneticist or a genetic counselor?

In a separate column next to each condition, physicians were instructed to write in the proportion referred.

(3) Did any issues arise in your clinical practice related to ethical or practical dilemmas surrounding how genetic information would be obtained or how it would be used?

If so, please describe your specific experiences.

Question 3 provided blank space for entirely open-ended responses.

Physicians were asked how many hours of continuing medical education about genetics they had participated in during the previous 2 years. They were also asked to rate, using a 5-point scale from "Easy" to "Unavailable," the accessibility of face-to-face and telephone consultation with geneticists and genetic counselors. Demographic information was elicited from respondents. For nonrespondents, gender, region, board certification, residency training, and year of graduation were available for comparison.

(See Table 1.)

Disorders with a prevalence of known genetic alterations of at least 1 in 5000 were chosen for potential inclusion in the survey. ${ }^{13-15}$ This threshold was based on an estimated panel of 1500 to 2000 patients per family physician, so that disorders on the list would have a high probability of having been encountered in practice. The list was reviewed by primary care physicians and geneticists who were consultants to the Genetics in Primary Care faculty development initiative, as part of the process of developing a curriculum in genetics for primary care educators. ${ }^{16}$ The list includes both multifactorial and Mendelian disorders that manifest at various ages. (Table 2 lists the conditions included in the questionnaire.) A few conditions (e.g., psychiatric disorders) were added because of recent media attention to their genetic aspects. Congenital metabolic disorders such as phenylketonuria (PKU) were included, although each is rare, because they are the target of universal newborn screening. An earlier version of the questionnaire was pilot-tested with 25 family physicians from various regions of the US, and revised to reflect their responses. The formal version of the questionnaire listed the genetic conditions in descending order according to the frequency with which the pilot sample reported having encountered them in practice.

\section{Sample}

A nationwide, random sample of 498 practicing family physician members of the American Academy of Family Physicians (AAFP) received the questionnaire by mail. Second and third mailings were sent to nonrespondents at approximately monthly intervals. A sample size calculation showed that 190 respondents provide $80 \%$ power (at an alpha level of 0.05 ) to detect a small difference of $5 \%$ to $10 \%$ in the proportion of physicians reporting having recently addressed a given genetic condition. AAFP member files were chosen as the sampling frame because demographic information is available for comparing respondents with nonrespondents and we could conveniently select a regionally stratified, random sample of family physicians including only those in active practice. Approximately $85 \%$ of U. S. family and general practitioners in office-based practice are members of the AAFP. ${ }^{17}$

\section{Data analysis}

Demographic descriptors of respondents and nonrespondents were compared. Descriptive data on each of the genetic conditions seen in clinical practice, the proportion referred, and the perceived ease of genetics consultation were generated and tested, using Chi square, two-tailed $t$ tests, and ANOVA, for differences by region of the country, urban versus rural practice location, physician demographics, and whether the physician provides prenatal care. Physicians' written comments, particularly those describing ethical and practical dilemmas related to the use of genetic information, were listed verbatim, independently categorized by three members of the research team, and the categories formalized by consensus. To estimate the number of cases referred for genetics consultation, we coded "more than 2 families" as 3 . The total number of cases referred for genetics consultation was then computed by totaling the number of families seen with the condition, and multiplying by the proportion referred. This estimate thus represents a minimum.

Finally, we wanted to discover whether physicians' reported likelihood of addressing the various genetic and familial conditions could be used to group the conditions into categories. A principle axis factor analysis with varimax rotation was performed on the frequencies of addressing the entire list of medical conditions. Factors were defined by genetic conditions with factor loadings greater than 0.30 (accounting for about $10 \%$ of the variance) in order to enhance interpretation of factors by focusing on the more stable associations.

\section{RESULTS}

\section{Physician demographics}

Table 1 shows the demographic characteristics of the sample, and comparisons with nonrespondents. The response rate was $38 \%$ (190/498). Respondents were similar to nonrespon- 
Table 1

Sample Demographics

\begin{tabular}{|c|c|c|c|c|}
\hline \multirow[b]{2}{*}{ Variable Difference } & \multicolumn{2}{|c|}{ Percent of } & \multirow[b]{2}{*}{$\mathrm{p}$ value } & \multirow[b]{2}{*}{$\begin{array}{l}\text { Practicing physician members of the } \\
\text { American Academy of Physicians }{ }^{a}\end{array}$} \\
\hline & $\begin{array}{l}\text { Respondents } \\
\mathrm{n}=190\end{array}$ & $\begin{array}{l}\text { Nonrespondents } \\
\quad \mathrm{n}=308\end{array}$ & & \\
\hline Gender: Male & 74 & 87 & $<.001$ & \\
\hline Year of Medical School Graduation & & & .20 & \\
\hline Before 1980 & 46 & 41 & & \\
\hline $1980-1989$ & 36 & 44 & & \\
\hline 1990 of after & 19 & 15 & & \\
\hline Board Certified in Family Practice & 96 & 93 & .21 & \\
\hline FP Residency Graduate & 87 & 84 & .47 & \\
\hline Region of the United States & & & .45 & \\
\hline Northeast & 22 & 17 & & \\
\hline Midwest & 34 & 32 & & \\
\hline South & 25 & 30 & & \\
\hline West & 20 & 20 & & \\
\hline Size of community where FPs practice & & & & N/A \\
\hline Rural or small town & 47 & & & \\
\hline Large town & 11 & & & \\
\hline Suburban & 29 & & & \\
\hline Urban & 12 & & & \\
\hline \multicolumn{5}{|l|}{ Percent of patients in Managed Care } \\
\hline Mean \pm standard deviation & $42 \pm 28$ & & & 37 \\
\hline $25 \%$ or less & 34 & & & \\
\hline $26 \%-50 \%$ & 31 & & & \\
\hline $51 \%-100 \%$ & 36 & & & \\
\hline \multicolumn{5}{|l|}{ Practice Arrangement } \\
\hline Solo Family Practice & 21 & & & 18 \\
\hline Family Practice Group & 53 & & & 51 \\
\hline Multispecialty group or Community Health Center & 25 & & & 22 \\
\hline Unknown & - & & & 9 \\
\hline Provide Prenatal Care ${ }^{b}$ & 37 & & & $\geq 31$ \\
\hline
\end{tabular}

${ }^{a}$ American Academy of Family Physicians ${ }^{17}$

${ }^{b}$ Respondents compared to proportion of AAFP members who provided intrapartum care in 2000. (Additional proportion of comparison group providing prenatal care unknown. ${ }^{25}$ )

dents except that a higher proportion of female physicians returned the survey.

\section{Self-reported frequency of addressing genetics issues}

Every responding physician reported having addressed at least one clinical condition from a genetic perspective in the past year. Table 2 shows the frequency with which genetic aspects of diseases on the list were addressed by responding physicians. Items in Table 2 are ordered by clusters from the factor analysis. The first cluster consists of common, multifactorial diseases; the second is a group of conditions more commonly addressed by physicians providing prenatal care; the third represents less frequently encountered genetic conditions. Physicians wrote in additional genetic conditions that they had encountered in the past year of practice, including Huntington disease, which was mentioned by $3 \%$, inflammatory bowel disease, cardiomyopathy, diabetes, incontinenti pigmenti, chromosomal translocations, familial melanoma, Tourette syndrome, Asberger syndrome, alpha-1 antitrypsin deficiency, cleft palate, and myotonic dystrophy.

The reported number of hours of recent CME related to genetics was positively related to the frequency of addressing 
Table 2

Proportion of family physicians who addressed genetic aspects of listed conditions

\begin{tabular}{|c|c|c|c|c|c|}
\hline & \multicolumn{2}{|c|}{ Percent of 190 physicians } & \multicolumn{3}{|c|}{ Number of families in one year ${ }^{a}$} \\
\hline & No & Yes & 1 & 2 & $>2$ \\
\hline \multicolumn{6}{|l|}{ Common, multifactorial conditions } \\
\hline Cardiovascular disease & 17 & 83 & 3 & 2 & 78 \\
\hline Family history of breast-ovarian cancer & 11 & 89 & 14 & 10 & 65 \\
\hline Family history of colon/endometrial cancer & 21 & 79 & 10 & 6 & 62 \\
\hline Family history of other cancers & 51 & 49 & 7 & 5 & 37 \\
\hline Alzheimer's disease & 22 & 78 & 14 & 15 & 49 \\
\hline \multicolumn{6}{|c|}{ Conditions more often addressed by family physicians providing prenatal care ${ }^{b}$} \\
\hline Abnormal number of chromosomes & 65 & 35 & 17 & 7 & 10 \\
\hline Infertility, stillbirth, multiple miscarriages & 69 & 31 & 14 & 6 & 10 \\
\hline Congenital abnormalities & 72 & 28 & 15 & 10 & 4 \\
\hline Mental retardation & 73 & 27 & 12 & 7 & 8 \\
\hline Neurofibromatosis & 75 & 25 & 20 & 4 & 2 \\
\hline PKU, congenital metabolic disorders & 88 & 12 & 10 & .5 & 2 \\
\hline \multicolumn{6}{|l|}{ Other familial/genetic conditions ${ }^{\mathrm{b}}$} \\
\hline Mental illness other than dementia & 52 & 48 & 10 & 9 & 30 \\
\hline Blood clotting disorder & 58 & 42 & 23 & 10 & 10 \\
\hline Hemoglobin disorder & 58 & 42 & 17 & 10 & 15 \\
\hline Hemochromatosis & 63 & 37 & 20 & 9 & 7 \\
\hline Vision or hearing problem & 68 & 32 & 12 & 5 & 15 \\
\hline Marfan syndrome & 84 & 16 & 12 & 3 & 2 \\
\hline Cystic fibrosis & 89 & 11 & 9 & .5 & 2 \\
\hline Tay-Sachs disease & 98 & 2 & .5 & 0 & 1 \\
\hline
\end{tabular}

${ }^{a}$ Percents are rounded to nearest integer and therefore the total in column two may differ slightly from the sum of columns three, four, and five.

${ }^{b}$ Ordered according to Factor Analysis, in three correlated groups of conditions.

genetic conditions in practice. Physician gender, year of medical school graduation, and practice setting were not associated with the frequency of addressing genetic aspects of any of the groups of conditions (data not shown).

\section{Referrals to geneticists}

Most cases where genetics issues were addressed were not referred for genetics consultation. Table 3 shows, for each condition, the proportion of all respondents who had referred at least one family to a geneticist in the past year (column 1), and estimates the number of referrals per 100 respondents (column 3). The most common referrals were for perinatal conditions and for genetics assessment of a family history of cancer. Column 2 of Table 3 omits physicians who did not encounter a given condition, and shows the proportion of physicians addressing a given condition who made a genetics referral.

\section{Accessibility of genetics consultation:}

Table 4 shows that $24 \%$ of all respondents said that genetics consultation is very difficult to obtain or unavailable to their patients. Most suburban and urban family physicians said that genetics consultation was easy to obtain, while $31 \%$ of rural and small town practitioners said that face-to-face genetics consultation is very difficult or unavailable. Eleven percent of respondents practice more than a 2 hour drive from a genetics consultant. Perhaps because genetics referrals were uncommon, we found no difference in the self-reported referral rates of physicians who expressed difficulty obtaining genetics consultation versus those without difficulty $(P=0.36$, data not shown), nor for rural and small town physicians compared to urban/suburban physicians ( $P=0.54$, data not shown).

\section{Ethical and social dilemmas related to genetic information}

Eighteen percent of respondents listed ethical and social dilemmas that arose when considering whether to pursue genetic diagnosis. The most common comment (from 7 physicians) was that families chose not to pursue genetic testing for BRCA mutations or other adult disorders (colon cancer, thrombophilia) because they feared insurance discrimination. Table 5 lists a wide variety of other ethical and social issues encoun- 
Table 3

Referrals to geneticists

\begin{tabular}{|c|c|c|c|}
\hline $\begin{array}{c}\text { Genetically-related } \\
\text { conditions, from most to } \\
\text { least frequently referred }\end{array}$ & $\begin{array}{l}\text { Proportion of physicians } \\
\text { who referred at least } \\
1 \text { family in past year } \\
(\mathrm{n}=190), \%\end{array}$ & $\begin{array}{l}\text { Proportion of physicians } \\
\text { addressing a condition } \\
\text { who referred at least } \\
\text { one such case for } \\
\text { genetics consultation, \% }\end{array}$ & $\begin{array}{c}\text { Estimated minimum } \\
\text { number of referrals } \\
\text { per hundred } \\
\text { physicians }\end{array}$ \\
\hline Family history of breast-ovarian cancer & 13 & 14 & 22.1 \\
\hline Chromosome abnormalities & 12 & 33 & 20.5 \\
\hline Congenital anomalies & 14 & 48 & 19.5 \\
\hline Infertility, stillbirth, miscarriages & 8 & 27 & 14.2 \\
\hline Blood clotting disorder & 7 & 16 & 11 \\
\hline Hemochromosis & 5 & 14 & 6.8 \\
\hline Family history of colon cancer & 5 & 7 & 6.8 \\
\hline Neurofibromatosis & 5 & 20 & 6.3 \\
\hline Marfan syndrome & 5 & 29 & 5.8 \\
\hline Mental retardation & 4 & 14 & 4.7 \\
\hline Hemoglobinopathy & 2 & 10 & 3.7 \\
\hline Congenital metabolic disorder & 3 & 22 & 3.7 \\
\hline Cystic fibrosis & 2 & 19 & 2.6 \\
\hline Family history of other cancer & 2 & 3 & 1.6 \\
\hline Mental illness other than dementia & .5 & 1 & 1.1 \\
\hline Cardiovascular disease & .5 & $<1$ & .5 \\
\hline Alzheimer's disease & .5 & $<1$ & .5 \\
\hline Vision or hearing problem & .5 & 2 & .5 \\
\hline Tay-Sachs disease & 0 & 0 & 0.0 \\
\hline
\end{tabular}

tered by family physicians whose patients considered or pursued genetic diagnosis.

\section{DISCUSSION AND CONCLUSIONS}

Compared to other recent surveys, ${ }^{8,18-22}$ this study is unique in reporting on a nationally representative sample of family physicians regarding a wide variety of heritable conditions. Although the data were collected in 2000-2001, our review of published literature and discussions with other researchers lead us to believe that the findings presented here are representative of current family practice. The sample includes a substantial proportion of rural and small-town physicians, underrepresented in other studies from urban centers where geneticists are more abundant. The national data presented here complement findings forthcoming from the Genetics Workforce Study, which used qualitative methods to describe in depth genetics services and the organization of health care in a few metropolitan areas? ${ }^{23}$ Most previous data from primary care clinicians have focused on narrower groups of conditions, such as cancer or prenatal genetic screening, not a full range of heritable conditions likely to be encountered in family practice.
Despite a 38\% response rate, not unusual for questionnaires to practicing physicians, ${ }^{24}$ those who responded to this survey are likely to be representative of family physicians practicing in the United States in terms of geographic region, age, and practice type. ${ }^{17}$ Unmeasured factors related to interest in this topic may separate respondents from nonrespondents. More respondents were women, but among respondents, physician gender was not associated with the likelihood of addressing genetic aspects of medical conditions or referring for genetics consultation. Thirty-seven percent of family physicians responding to this survey were providing prenatal care. Nationally, 31\% of AAFP member physicians provided prenatal and intrapartum care in $2000,{ }^{25}$ with an unknown number of additional physicians providing prenatal care alone. These data are limited by being self-reported and subject to biased recollection. We attempted to minimize the tendency to nonspecifically endorse items listed on the survey by asking physicians to recall their management of a small number of particular families and by encouraging respondents to write in additional examples of clinical situations that they had encountered. Unlike the HuGEM survey ${ }^{26}$ this brief questionnaire did not allow us to determine more specifically the ways in which physicians "addressed" genetic aspects of medical conditions, nor their 
Table 4

Family physicians' access to genetics expertise

\begin{tabular}{|c|c|}
\hline Variable & Respondents, \% $(\mathrm{n}=190)$ \\
\hline \multicolumn{2}{|l|}{ Hours of CME in genetics, past 2 years } \\
\hline None & 59 \\
\hline 0.5 to 2 hours & 28 \\
\hline More than 2 hours $(3-150)$ & 13 \\
\hline \multicolumn{2}{|c|}{$\begin{array}{l}\text { Driving time from practice site to genetics consultant, minutes; } \\
\text { Mean }=68 \pm 63 \text { minutes }\end{array}$} \\
\hline 30 minutes or less & 38 \\
\hline 31 to 60 minutes & 26 \\
\hline 61 to 120 minutes & 25 \\
\hline More than 120 minutes & 11 \\
\hline \multicolumn{2}{|l|}{ Accessibility of genetics consultation } \\
\hline \multicolumn{2}{|l|}{ Face-to-face } \\
\hline Easy & 33 \\
\hline Somewhat difficult or difficult & 44 \\
\hline Very difficult or not available & 23 \\
\hline \multicolumn{2}{|l|}{ Remote } \\
\hline Easy & 42 \\
\hline Somewhat difficult or difficult & 37 \\
\hline Very difficult or not available & 21 \\
\hline
\end{tabular}

level of comfort in doing so. This study had no way to assess underreporting.

We found that nationwide, family physicians address a wide variety of genetics issues with patients. Fifteen of the 19 categories of medical conditions in this survey were addressed with at least one patient by more than $25 \%$ of family physicians in the past year, as had been predicted from the frequency of these disorders in the general population. The majority of family physicians discuss with patients the familial factors that contribute to common, multifactorial conditions such as cancer and cardiovascular disease, and some have referred patients for cancer genetic testing. In addition, front line, primary care physicians are indeed encountering with their patients the full gamut of ethical and social issues that have recently been delineated in relation to predictive and prenatal genetic testing. ${ }^{27-30}$ At the same time it is important to recognize that the frequency with which genetics issues are addressed is small in comparison with other conditions seen in primary care? ${ }^{31}$ Thus increasing the salience of genetics among the competing demands of family practice is likely to remain a challenge. Moreover, variability among practice settings, patient comorbidities, and physicians' clinical interests precludes establishing universal guidelines for consultation and referral.

The single most common reason for referral to a geneticist was a family history of breast -ovarian cancer; $13 \%$ of respondents had referred at least one such patient during the previous year and 5\% had made referrals for a family history of colon cancer. These findings are comparable to rates of referral for
Table 5

Ethical and social genetics issues encountered by family physicians

\begin{tabular}{|c|c|}
\hline Issue & $\begin{array}{l}\text { Number of Physicians } \\
\text { that mentioned issue }\end{array}$ \\
\hline \multicolumn{2}{|l|}{ Insurance related issue } \\
\hline Families feared insurance discrimination & 7 \\
\hline High cost of DNA costs & 5 \\
\hline Lack of insurance coverage & 4 \\
\hline \multicolumn{2}{|l|}{ Challenging decisions for patients } \\
\hline Difficult reproductive choices & 6 \\
\hline $\begin{array}{l}\text { Potential harms of genetic tests, compared to } \\
\text { limited expected benefits }\end{array}$ & 6 \\
\hline \multicolumn{2}{|l|}{ Ethical dilemmas for physician } \\
\hline Risk of disclosing nonpaternity & 2 \\
\hline $\begin{array}{l}\text { Patients' refusal to disclose risk of a serious } \\
\text { genetic disorder to relatives sharing the } \\
\text { physician }\end{array}$ & 2 \\
\hline \multicolumn{2}{|l|}{ Unclear guidelines } \\
\hline $\begin{array}{l}\text { "Appropriate age to screen for carriers of a genetic } \\
\text { disorder that might affect reproductive } \\
\text { decision-making" }\end{array}$ & 1 \\
\hline $\begin{array}{l}\text { "Should BRCA testing be ordered by the primary } \\
\text { care physician, or the oncologist or geneticist" }\end{array}$ & 1 \\
\hline
\end{tabular}

cancer genetics assessment by primary care physicians of $23 \%$ in a 2000-2001 national survey ${ }^{18}$ and rates ranging from 19\% to $37 \%$ in several regional surveys. ${ }^{19-21,32}$ Our data do not show whether family physicians ordered and interpreted genetic tests for cancer susceptibility without consultation. Wideroff et al. ${ }^{16}$ found that $3 \%$ of US. family physicians reported having ordered a test for hereditary breast cancer and $2 \%$ had ordered a test for hereditary colon cancer, but most $(23 \%)$ referred patients to geneticists or oncologists for cancer risk assessment. Studies in Britain, ${ }^{33-35}$ Canada, $^{10}$ and the United States ${ }^{8,20,36}$ show an immediate need for further education and decision support for primary care physicians regarding assessment of hereditary cancer susceptibility.

Those physicians who provide prenatal care were most likely to have dealt with infertility, pregnancy losses, chromosomal abnormalities, congenital anomalies, and some of the pediatric genetic disorders, a cluster which accounted for the largest number of genetics referrals overall. Family physicians who provide prenatal care already have well-established, regional patterns for prenatal genetic screening and referral. ${ }^{37,38}$

Possibly, systems of care can build on these patterns and relationships between consultants and primary care clinicians when considering how to provide other genetics services.

Family physicians reported referring to genetic specialists only a minority of the families seen with genetically-related conditions. In general, the rarer genetic conditions, when seen, were more likely to be referred to geneticists. However, some conditions, e.g., Tay-Sachs disease, may be preempted by the community and self-referred, with the family physician not 
involved in the process. It is also unknown how many cases are referred, not to geneticists, but to other consultants for evaluation of familial disorders; for example, to gastroenterologists because of a family history of colorectal cancer, or to hematologists for thrombophilias, bleeding disorders, and hemoglobinopathies. Finally these data do not show whether the families who were referred actually obtained genetics consultation.

Because this survey asked if the family had been referred during the past year, our results do not show the proportion of cases that may previously have had genetics consultation. Little is known about the longitudinal aspects of counseling patients in primary care who may be candidates for genetics assessment, nor how many patients initially declining referral will subsequently arrive at a point where it makes sense to consult a geneticist. ${ }^{39}$

Respondents' written comments hint at circumstances that lead some patients and family physicians to choose not to pursue genetics assessment. Most commonly these had to do with patients' fears of becoming uninsurable as a result, the high cost of testing, or consideration that the harms of discovering some genetic information would be greater than the benefits. Some physicians cited a need for more evidence about the clinical utility of $B R C A$ mutation testing. ${ }^{40-42}$ Research programs that have provided free counseling and testing to individuals in families with hereditary cancer have found that one third or more refused counseling despite being potentially at high risk. ${ }^{43-45} \mathrm{~A}$ few comments on our survey suggest that patients' refusal of referral despite a strong family history can sometimes be frustrating to the family physician. Research that leads to better understanding how people perceive and act on familial disease susceptibility may improve clinical approaches to resolving such impasses. ${ }^{39,46,47}$

Our data show that the questions that family physicians address without referral often center on common, multifactorial diseases such as cardiovascular disease, dementia, or mental illness. This pattern reflects the current state of knowledge: family history is known to be a strong risk factor but currently available genetic testing has low clinical utility because it imperfectly predicts disease and does not usually suggest distinct treatment or preventive measures. ${ }^{7}$ In contrast, families with conditions such as hereditary cancer susceptibility, for which genetic tests that could change preventive strategies are available, were more frequently referred to geneticists. Responses to this survey suggest a highly relevant focus for geneticists and genetic epidemiologists to contribute to professional education for primary care clinicians. ${ }^{41}$ The clinical utility and empirical benefits versus harms of genetics assessment for common diseases are topics about which family physicians need and are likely to want to receive updated evidence as it becomes available. $^{48}$

Finally, these data show that a substantial minority of US family physicians practice in settings where they perceive genetics consultation to be inaccessible. Koil and others have also found barriers to genetics consultation to be stronger for rural physicians. ${ }^{11,20}$ The finding that $11 \%$ of patients would have to drive for more than 2 hours to see a geneticist reinforces cur- rent interest in telemedicine as a means of providing remote consultations, ${ }^{49}$ and highlights the coming need for more trained genetics consultants and/or for enhanced genetics training within primary care. ${ }^{50,51}$

Social policy, regional planning, and innovative methods for providing expert genetics consultation and counseling must address the need to make genetics expertise universally accessible. ${ }^{52,53}$

\section{Significance of this research}

Genetics specialists, primary care educators, government and professional societies have recently joined to plan and disseminate several professional and public genetics education initiatives ${ }^{47,54-61}$ New models are being developed to expand professional training in genetics. In this context, it is important to know what front-line, primary care physicians in varied settings recognize as the most relevant genetics-related clinical issues that they encounter in practice. Data such as those from this survey can form a starting point for planning educational activities, providing information resources, setting policy priorities, and organizing consultation facilities for family physicians and their patients. The groups of conditions found by factor analysis may provide an empirical framework for organizing services and targeting education. Future research that repeats the survey could measure temporal trends in recognition and referral for genetic conditions, and could collect comparison data from internists or other groups of primary care clinicians.

\section{ACKNOWLEDGMENTS}

This work was supported by the following grants: Establishment of Departments of Family Medicine, HRSA Award no. PE -15024 (Smith, Kc., PI); Translational Resource Oncology Training Grant, NCI, K12 Award to Louise Acheson (Distelhorst, C, PI); Mentored Research Career Development Award in Cancer Prevention and Control, NCI, K07 Award no. CA86958 (Acheson, LS., PI); Cancer Prevention and Control, NCI, K24 Award no. CA-81031 (Stange, KC., PI); Value of Family Practice, AAFP Research Center Grant (Stange, Kc., PI). The authors thank Amy Artim Tapolyai for data management and analysis and for her contributions to survey design.

\section{References}

1. Emery J, Watson E, Rose P, Andennann A. A systematic review of the literature exploring the role of primary care in genetic services. Family Pract. 1999;16:426-445.

2. Emery J, Hayflick S. The challenge of integrating genetic medicine into primary care. BMJ 2001;322:1027-1030.

3. Worthen HG. Inherited cancer and the primary care physician: Barriers and strategies. Cancer 1999;86(Suppl):2583-2588.

4. Burke W, Press N, Pinsky L. Breast carcinoma from a primary care perspective. Cancer 1997;80:621-626.

5. Medalie JH, Zyzanski SJ, Langa D, Stange Kc. The family in family practice: Is it a reality? J Fam Pract 1998;46:390-396.

6. Holtzman N, Marteau T. Will genetics revolutionize medicine? N Engl J Med 2000; 343:141-144.

7. Evans JP, Skrzynia C, Burke W. The complexities of predictive genetic testing. BMJ 2001;322:1052-1056.

8. Centers for Disease Control and Prevention (CDC). Genetic testing for breast and ovarian cancer susceptibility: evaluating direct-to-consumer marketing-Atlanta, 


\section{Acheson et al.}

Denver, Raleigh-Durham, and Seattle, 2003. MMWR Morb Mortal Wkly Rep.. 2004 Jul16 2004;53:603-606.

9. Hayflick SJ, Eiff MP. Role of primary care providers in the delivery of genetics services. Community Genet 1998;1:18-22.

10. Carroll J, Brown J, Blaine S, Glendon G, Pugh P, Medved W. Genetic susceptibility to cancer. Family physicians' experience. Canadian Family Physician 2003;49:45-52.

11. Fineman R, Doyle D. Public health needs assessment for state-based genetic services delivery. In: Khoury, M, Burke W, Thomson E, eds. Genetics and Public Health in the 21st Century. Vol 40. Oxford: Oxford University Press;2000:261272.

12. Suther S, Goodson P. Barriers to the provision of genetic services by primary care physicians: a systematic review of the literature. Genet Med 2003;5:70-76.

13. Kingston H. ABC of Clin Genet Second ed: Blackwell Publishing Co.; 1997.

14. Jorde L, Bamshad M, Carey J, White R. Medical Genetics. Second ed. Philadelphia: Elsevier Science Health Science Division; 2000.

15. Sack GH. Medical Genetics. 1 ed. New York: McGraw-Hill Health Professions Division; 1999;2:383-594.

16. Burke W, Genetics Education Committee. Genetics in Primary Care Curriculum Afaculty development initiative: Contract to the Society of Teachers of Family Medicine, funded by the Maternal and Child Health Bureau and the Bureau of Health Professions ofHRSA with co-funding from the National Human Genome Research Institute, National Institutes of Health, and the Agency for Healthcare Research and Quality; Revised Sept., 2001.

17. American Academy of Family Physicians. Facts aboutfamily practice Accessed November 17, 2004

18. Wideroff L, Freedman A, Olson L, et al. Physician use of genetic testing for cancer susceptibility. Cancer Epidemiology Biomarkers \& Prevention 2003;12:295-303.

19. Sifri R, Myers R, Hyslop T, et al. Use of cancer susceptibility testing among primary care physicians. Clin Genet 2003;64:355-360.

20. Koil C, Everett J, Heoechstetter L, Ricer R, Huelsman K. Differences in physician referral practices and attitudes regarding hereditary breast cancer by clinical practice location. Genet Med 2003;5:364-369.

21. Acton R, Burst N, Casebeer L, et al. Knowledge, attitudes, and behaviors of Alabama's primary care physicians regarding cancer genetics. Acad Med 2000;75:850 852.

22. Gramling R, Nash J, Siren K, Culpepper L. Predictive genetics in primary care: Expectations for the motivational impact of genetic testing affects the importance family physicians place on screening for familial cancer risk. Genet Med 2003;5:172175.

23. Assessing Genetic Services and the Health Workforce. Toward a research agenda: Health services research in genetics. Report of Annual meeting of the Advisory Council, Genetic services and health workforce research center; November 17,2003; University of Maryland, Baltimore, MD.

24. Baron G, De Wals P, Milord F. Cost-effectiveness of a lottery for increasing physicians' responses to a mail survey. Eval Health Prof March, 2001;24:47-52.

25. American Academy of Family Physicians. Facts about family practice. Leawood, Kansas January 12, 2000.

26. Lapham E, Kozma C, Weiss J, Benkendorf J, Wilson M. The gap between practice and genetics education of health professionals: HuGEM survey results. Genet Med July/August 2000;2:226-231.

27. Mahowald MB, McKusick VA, Scheuerle AS, Aspinwall TJ, eds. Genetics in the Clinic: Clinical, Ethical, and Social Implicationsfor Primary Care. 1 ed. St. Louis, MO: Mosby; 2001.

28. Juengst E. The ethics of prediction: Genetic risk and the physician-patient relationship. Genome Science and Technology 1995;1:21-36.

29. Rothstein M, ed. Genetic Secrets: Protecting privacy and cOlifidentiality in the genetic era. 1 ed. New Haven, CT: Yale University Press; 1997.

30. Buchanan A, Brock DW, Daniels N, Wikler D. From Chance to Choice: Genetics and Justice. First ed. Cambridge, England: Cambridge University Press; 2000.

31. Stange KC, Zyzanski SJ, Jaen CR, et al. Illuminating the 'Black Box': A description of 4454 patient visits to 138 family physicians. J Fam. Pract 1998;46:377-389.

32. Friedman LC, PIon SE, Cooper HP, Weinberg AD. Cancer genetics - survey of primary care physicians' attitudes and practices. J Cancer Educ 1997;12:199-203.

33. Rose P, Watson E, Yudkin P, et al. Referral of patients with a family history of breast/ovarian cancer-GPs' knowledge and expectations. Fam Pract 2001;18:487_ 490

34. Watson E, Clements A, Yudkin P, et al. Evaluation of the impact of two educational interventions on GP management of familial breast/ovarian cancer cases: a cluster randomized controlled trial. Br J Gen Pract 2001;51:817-821.
35. Watson E, Austoker J, Lucassen A. A study of GP referrals to a family cancer clinic for breast/ovarian cancer. Family Practice 2001;18:131-134.

36. Freedman A, Wideroff L, Olson L, et al. US physicians' attitudes toward genetic testing for cancer susceptibility. Am J Med Genet 2003;120A:63-71.

37. Acheson L. Genetic Interventions; Possible indicators of fetal abnormalities. In: Ratcliffe, S, Baxley L, Byrd J, Sakombut E, eds. Family Practice Obstetrics. Second ed. Philadelphia: Hanley \& Belfus;2001;107-111; 184-192.

38. PRimary Ob Genetic Risk Assessment and Management in Maine. ed. Scarborough, ME: Foundation for Blood Research; 1997.

39. Martin JR, Wilikovsky AS. Genetic counseling in primary care: Longitudinal, psychosocial issues in genetic diagnosis and counseling. Primary Care Clinics in Office Practice. 2004;31:509-524.

40. Press N, Yasui Y, Reynolds S, Durfy S, Burke W. Women's interest in genetic testing for breast cancer susceptibility may be based on unrealistic expectations. Am J Med Genet 2001;99:99-110.

41. Burke W, Atkins D, Gwinn M, et al. Genetic test evaluation: information needs of clinicians, policy makers, and the public. Am J Epidemiol 2002;156:311-318.

42. Griffith G, RT E, J G, et al Estimating the survival benefits gained from providing national cancer genetic services to women with a family history of breast cancer. $\mathrm{BrJ}$ Cancer May 17,2004;90:1912-1919.

43. Lerman C, Hughes C, Lemon SJ, et al. What you don't know can hurt you: Adverse psychologic effects in members of BRCAl-linked and BRCA2-linked families who decline genetic testing. J Clin Oncol 1998;16:1650-1654.

44. Lerman C, Hughes C, Trock B, et al. Genetic testing in families with hereditary nonpolyposis colon cancer. JAMA 1999;281:1618-1622.

45. Lynch H, Lemon S, Durham C, et al. A descriptive study ofBRCAl testing and reactions to disclosure of test results. Cancer 1997;79:2219-2228.

46. Walter F, Emery J, Braithwaite D, Marteau T. Lay understanding of familial risk of common, chronic diseases: A systematic review and synthesis of qualitative research. Annals of Fam 2004;3:583-594.

47. Burke W, Acheson L, Botkin L, et al. Genetics in Primary Care: A USA faculty development initiative. Community Genetics 2002;5:138-146.

48. Khoury M. Genetics and genomics in practice: the continuum from genetic disease to genetic information in health and disease. Genet Med Jul-Aug 2003;5:261-268.

49. Lea DH, Johnson JL, Ellingwood S, Allan W, Patel A, Smith R. Telegenetics in Maine: Successful clinical and educational service delivery model developed from a 3-year pilot project. Genet Med January, 2005;7:21-27.

50. Riegert-Johnson DL, Korf BR, Alford RL, et al. Outline of a medical genetics curriculum for internal medicine residency training programs. Genet Med November/ December, 2004;6:543-547.

51. Blazer KR, MacDonald DJ, Ricker C, Sand S, Uman GC, Weitzel IN. Outcomes from intensive training in genetic cancer risk counseling for clinicians. Genet Med January 2005;7:40-47.

52. Touchette N, Holtzman NA, Davis JG, Feetham S, Collins FS. Toward the 21st Century: Incorporating Genetics Into Primary Health Care. Plainview, NY: Cold Spring Harbor Laboratory Press; 1997.

53. Kinmonth AL, Reinhard J, Bobrow M, Pauker S. The new genetics. Implications for clinical services in Britain and the United States. BMJ 1998;316:767-770.

54. Acheson LS, Root S, Tyler Cl. Clinical Genetics. Home Study Self-Assessment monograph. 240 ed. Kansas City: American Academy of Family Physicians; 1999.

55. American Medical Association. Genetic Medicine for the Primary Care Physician; March, 1998; New Orleans, LA.

56. American Medical Association, American Gastroenterological Association. Identifying and managing risk/or Hereditary Nonpolyposis Colorectal Cancer and Endometrial Cancer (HNPCC) May, 2001

57. National Coalition for Health Professional Education in Genetics. Educational resources available at http://www.nchpeg.org. Accessed August 12, 2005.

58. American Medical Association. Identifying and Managing Hereditary Risk/or Breast and Ovarian Cancer. Chicago, IL: American Medical Association; 2001.

59. American Academy of Family Physicians. Annual Clinical Focus: Genomics. American Academy 0/ Family Physicians. Accessed October 14, 2004.

60. U.S. Surgeon General. U.S. Surgeon General's Family History Initiative. Available at: http://www.hhs.gov/familyhistory/. Accessed November 9,2004.

61. National Society of Genetic Counselors. NSGC Consumer Resources: Family History; Genetic Discrimination; Counselors. NSGc. Available at: http://www.nsgc.org/ consumer/. Accessed November 18,2004 